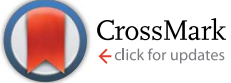

Cite this: RSC Adv., 2017, 7, 14309

Received 30th December 2016 Accepted 22nd February 2017

DOI: $10.1039 / c 6 r a 28844 h$

rsc.li/rsc-advances

\section{Highly selective synthesis of large aromatic molecules with nano-zeolite: beyond the shape selectivity effect $\uparrow$}

\author{
Yilin Hou, ${ }^{a}$ Ning Wang, ${ }^{a}$ Jianmei Zhang ${ }^{b}$ and Weizhong Qian*a
}

Nano ZSM-12 zeolite, with a huge external surface area and lower ratio of Brönsted to Lewis acids, exhibited high activity and selectivity for the direct transformation of methanol into multi-methylbenzenes with molecule sizes that were larger than the 1-D pore of ZSM-12, via the production of xylene inside the pore and complete external surface methylation.
Zeolites ${ }^{1-4}$ with clearly defined pore structures or channel sizes exhibit shape selective effects on molecules with certain sizes and, consequently, are crucial to molecule separation ${ }^{1,5}$ and the production of desirable olefins or aromatics in SAPO-34 or ZSM$5 .^{6-11}$ Recently, such an effect was expanded to encapsulate the metal active site inside the channel of the zeolite, so as to increase product selectivity under tough reaction conditions. ${ }^{12-16}$ However, this method is only effective for producing molecules with the same or smaller sizes than the pore. One is unable to use zeolites to directly prepare molecules with sizes larger than the pore, due to consideration of the pore blockage effect. On the other hand, the huge external surfaces of nanosized zeolites, as catalysts, always result in undesirable, uncontrollable side reactions, ${ }^{9-11}$ which always decrease the yield of the desired product significantly and are considered as one of the major drawbacks of nanosized zeolites.

Herein, we address an idea that combines the two aforementioned effects together for the highly selective synthesis of aromatics with sizes that are larger than the channel size of the host zeolite (Fig. 1a). For the study, we used the nanosized ZSM12 zeolite with a 1-D channel $(0.57 \times 0.61 \mathrm{~nm})$ to produce multimethylbenzenes (MMBs) such as tetra-, penta- or hexamethylbenzene, with molecule sizes of $0.7-0.9 \mathrm{~nm}$, in a model methanol to aromatics (MTA) reaction. The selectivity of the MMBs for all aromatics, transformed directly from methanol, was $84.6 \%$. Characterization of the coke validated that the micropores of ZSM-12 were fully filled with coke, resulting in the formation of few intermediates inside the 1-D channel. The lower ratio of Brönsted/Lewis acids of ZSM-12 inhibits the dealkylation of xylene (X) to B and T, and also contributes to the

${ }^{a}$ Department of Chemical Engineering, Tsinghua University, 100084, China. E-mail: qianwz@tsinghua.edu.cn

${ }^{b}$ School of Mechanical and Vehicle Engineering, Changzhou Institute of Technology, Jiangsu, 213002, China

$\dagger$ Electronic supplementary information (ESI) available. See DOI: 10.1039/c6ra28844h increased yield of MMBs. External silanization of the ZSM-12 surface validated that the methylation of tri-methylbenzene (triMB) directly depends on the external acids. This confirmed that the production of MMBs proceeded first by the formation of $\mathrm{X}$ inside the pores, and second by the subsequent methylation of $\mathrm{X}$ on the huge external surface of the zeolite.

To the best of our knowledge, ZSM-12 was previously used in other reaction systems, but has never been used in the MTA
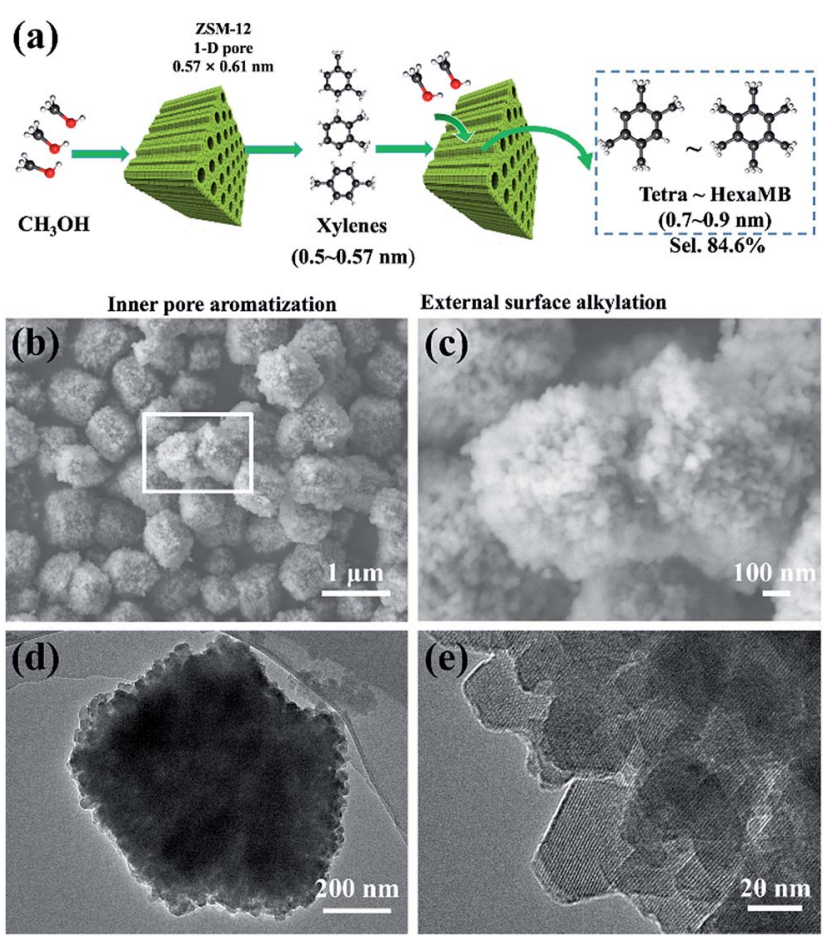

Fig. 1 (a) Proposed technical route for the preparation of multimethylbenzenes from methanol using a nano ZSM-12 zeolite-based catalyst. (b) SEM image of H-ZSM-12. (c) High-resolution SEM image of $\mathrm{H}$-ZSM-12. (d) TEM image of H-ZSM-12. (e) High-resolution TEM image of $\mathrm{H}-\mathrm{ZSM}-12$. 
reaction. ${ }^{17-19}$ In addition, the conventional route for the production of MMBs called for expensive starting reactants (phenol or xylene), or for the separation of MMBs (<1-5\% in $\mathrm{C}_{9}-$ $\mathrm{C}_{12}$ components, in the catalytic reforming of naphtha) from others with high energy consumption. ${ }^{20-22}$ From this point of view, the direct production of MMBs, for use as dyes or plasticizers, from one reactant (methanol) represents great progress. Considering the various choices of zeolite and zeolite catalyzed reactions, our idea may be developed as a general approach towards simplifying the synthesis routes of larger molecules beyond the shape selectivity effect of zeolites.

Experimentally, ZSM-12 was synthesized by a modified hydrothermal method (ESI S1 $\dagger$ ), ${ }^{23}$ using tetraethylammonium hydroxide (TEAOH), sodium aluminium oxide $\left(\mathrm{Na}_{2} \mathrm{Al}_{2} \mathrm{O}_{4}\right)$ and colloidal silica $(40 \%$ in water). Nanosized ZSM-5 was also synthesized for comparison, following the previously reported method. ${ }^{25}$ The as-prepared aggregates of ZSM-12 had sizes of 0.5-1.5 $\mu \mathrm{m}$ (Fig. 1b and c), and were composed of single-crystal nanoparticles with diameters of 20-30 nm (Fig. 1d and e). All of the peaks in the XRD pattern (Fig. 2a) were attributed to the phases of the ZSM-12 zeolite. No signals corresponding to amorphous $\mathrm{Si}$ or $\mathrm{Al}$ species or other zeolites (e.g. ZSM-5) were detected in the $2 \theta$ range of $5-35^{\circ}$. EDS characterization showed that the $\mathrm{Si} / \mathrm{Al}$ ratio of the sample was 36.03 , which was very close to the ratio (40) in the precursor. This confirmed that the ZSM12 sample was of high purity. $\mathrm{N}_{2}$-adsorption tests showed typical type-I and type-IV adsorption-desorption curves, thus indicating that the ZSM-12 sample had a remarkable micro-/ mesoporous structure (Fig. 2b). DFT calculations showed that the sample possessed two peaks at $1 \mathrm{~nm}$ and $6 \mathrm{~nm}$, which correspond to micropores and mesopores, respectively. The total volume of mesopores was $0.517 \mathrm{~cm}^{3} \mathrm{~g}^{-1}$, which accounted for $92.8 \%$ of the total pore volume. The BET surface area was
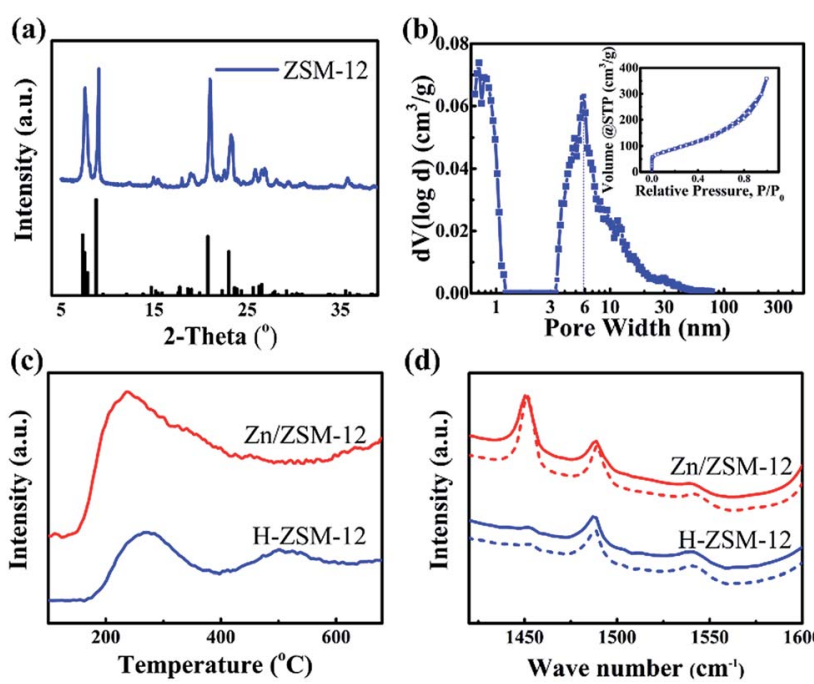

(d)

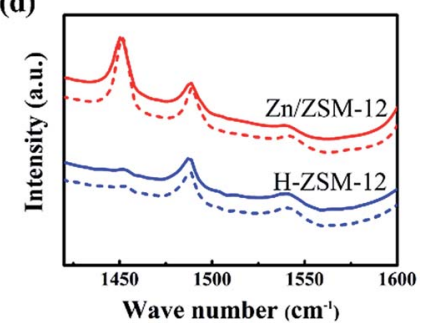

Fig. 2 (a) XRD image and PDF card of $\mathrm{H}-\mathrm{ZSM}-12$. (b) BET isothermal curve and pore size distribution of $\mathrm{H}-\mathrm{ZSM}-12$. (c) $\mathrm{NH}_{3}-\mathrm{TPD}$ spectrum of $\mathrm{H}-\mathrm{ZSM}-12$ and $\mathrm{Zn} / \mathrm{ZSM}-12$. (d) Py-IR spectrum of $\mathrm{H}-\mathrm{ZSM}-12$ and $\mathrm{Zn} / \mathrm{ZSM}-12$. The solid line is the desorption curve at $350{ }^{\circ} \mathrm{C}$ and the dashed line is the desorption curve at $200{ }^{\circ} \mathrm{C}$.
$310.8 \mathrm{~m}^{2} \mathrm{~g}^{-1}$, due to the presence of mesopores and the high external surface area of the nanocrystals.

$\mathrm{NH}_{3}$-TPD was used to determine the strengths and densities of the acid sites of H-ZSM-12 (Fig. 2c) and ZSM-5(Tables S1 and $\mathrm{S} 2 \dagger)$. The peak at around $300{ }^{\circ} \mathrm{C}$ was due to the contribution of the hydrogen bond of $\mathrm{NH}_{4}{ }^{+}$, and was therefore assigned to the weak acid sites. Another peak at $500{ }^{\circ} \mathrm{C}$ was assigned to the strong acid sites. Doping of the $\mathrm{Zn}$ species resulted in an increase in the amount of weak and medium acid sites, but a decrease in the amount of strong acid sites (Fig. 2c). The total acidic density of $\mathrm{Zn} / \mathrm{ZSM}-12$, which was calculated using quantitative ammonia calibration, was $0.629 \mathrm{mmol} \mathrm{g}^{-1}$, and the corresponding densities of the weak and medium acid sites were 0.261 and $0.368 \mathrm{mmol} \mathrm{g}^{-1}$ (Fig. S1†), respectively. In comparison, the acidic density of Zn/ZSM-5 was $0.912 \mathrm{mmol} \mathrm{g}^{-1}$ $(\mathrm{Si} / \mathrm{Al}=50) .{ }^{9} \mathrm{ZSM}-12$, with a lower amount of acid, is favourable for the suppression of dealkylation of $\mathrm{X}$, as discussed below. The interaction of zeolite with the $\mathrm{Zn}$ species changed the Brönsted acids to Lewis acids with lower acidic strengths. ${ }^{9}$ The types of acidic sites of ZSM-12 and the ratio of Brönsted/Lewis acids were determined by in situ Py-IR (Fig. 2d).

The ratios for the weak and strong acid sites of Zn/ZSM-12 were 0.167 and 0.151 , respectively, both of which were lower than the associated ratios ( 0.330 and 0.273 , respectively) of $\mathrm{Zn} /$ ZSM-5. ${ }^{9}$ In addition, the acid density of the external surface was $0.108 \mathrm{mmol} \mathrm{g}^{-1}, 17.2 \%$ in total, which was larger than that (12.8\%) of nano ZSM-5 (Fig. S2 $\dagger$ ). ${ }^{9}$ The present higher ratio of Lewis acids and higher ratio of external acids are favourable for the aromatization of methanol, and contribute to the high selectivity of MMBs via surface alkylation, as is discussed below.

For the catalytic performance of ZSM-12 (doped with 3\% Zn) in the MTA reaction, the conversion of methanol was above $99 \%$ after $12 \mathrm{~h}$ (Fig. 3a). Aromatics in large amounts were produced accordingly (Fig. 3b). The selectivity of the aromatics (carbon base) using nano ZSM-12 was higher than those with the two nano ZSM-5 samples. Although there existed an induction period (initial $5 \mathrm{~h}$ ) for the building of the hydrocarbon-pool inside the channel for the nanosized ZSM-5 and ZSM-12 catalysts, ${ }^{24}$ the larger pore sizes of the latter compared to those of the former may be the reason for the high selectivity of aromatics. In addition, the differences in pore size and acidity may result in the life time of nano ZSM-12 (Si/Al ratio of 36.03) being longer than that of nano ZSM-5 ( $\mathrm{Si} / \mathrm{Al}$ ratio of 30 ), but shorter than that of nano ZSM-5 (Si/Al ratio of 60) (Fig. 3a and b). This resulted in the high conversion of methanol, low yield of light hydrocarbons, higher but fluctuating yield of $\mathrm{B}$ and $\mathrm{T}$, and lower yield of MMBs in the induction period (Fig. 3c). After that, the selectivities of $\mathrm{B}$ and $\mathrm{T}$ (in 5-20 $\mathrm{h}$ in reaction) were both in very small amounts, and the dominant products were MMBs and other heavy components with similar melting points (Fig. 3c). Detailed product analysis carried out by GC-MS suggested that the aromatic products consisted of $1.08 \% \mathrm{C}_{6}-\mathrm{C}_{8}$, $1.92 \%$ triMB, $84.6 \%$ MMBs (23.4\% tetraMB, 50.9\% pentaMB and $10.3 \%$ hexaMB) and $12.4 \%$ naphthalene and other heavier components (Fig. S3 and S4 $\dagger$ ).

In contrast, the aromatic products when using nano ZSM-5 $(\mathrm{Si} / \mathrm{Al}=60)$ or nano ZSM-5 $(\mathrm{Si} / \mathrm{Al}=30)$ mostly consist of $\mathrm{X}$ 

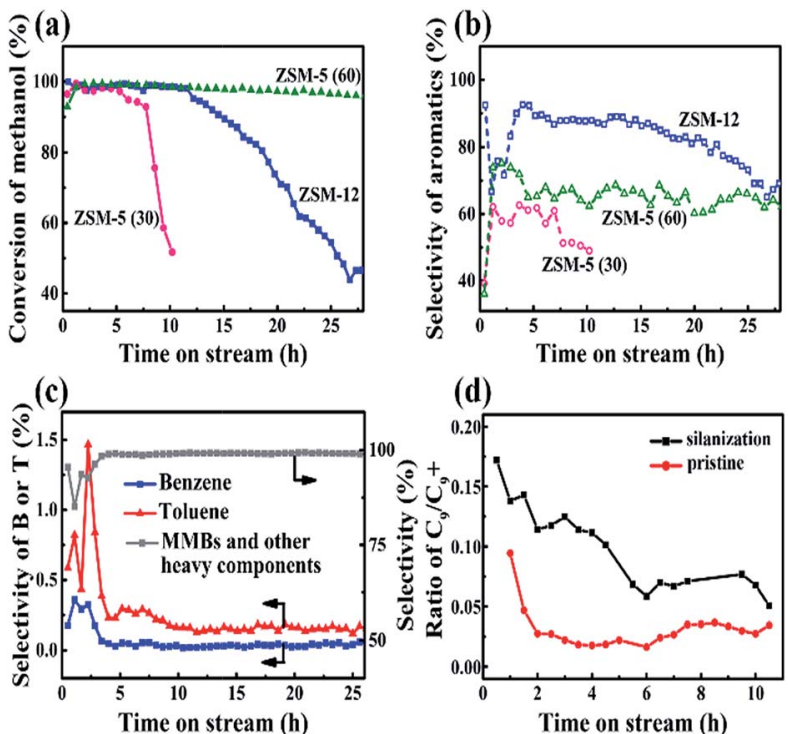

(d)

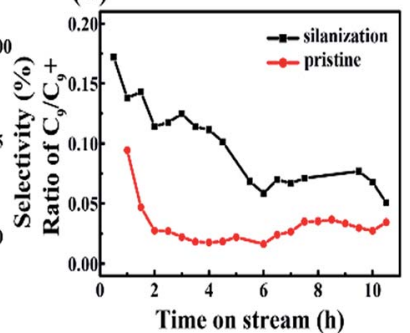

Fig. 3 (a) Time-dependent methanol conversions of Zn/ZSM-12, Zn/ ZSM-5 (30) and Zn/ZSM-5 (60). (b) Selectivity of aromatics for Zn/ZSM$12, Z n / Z S M-5$ (30) and Zn/ZSM-5 (60). (c) Selectivity of B, T and MMBs (and other heavy components) in aromatics using Zn/ZSM-12. (d) Ratio of $\mathrm{C}_{9} / \mathrm{C}_{9}{ }^{+}$with the catalyst, with or without silanization at different reaction times.

and triMBs. The weight ratio of MMBs is very small. ${ }^{25}$ Seemingly, the product distribution is not only related to the pore size, but also to the acidities of the different zeolites. ZSM-12, with a larger channel, weaker acids and a lower ratio of Brönsted/Lewis acids, compared to ZSM-5, gave products containing less $\mathrm{B}$ and $\mathrm{T}$, but aromatics with larger molecular sizes.

To understand in depth the high selectivity of MMBs when using ZSM-12, a silicane (3-aminopropyltriethoxysilane, APTES), with a larger size than the channel size of ZSM-12, was used to decorate the surface of ZSM-12. ${ }^{26,27}$ The effect of APTES is to reduce the external acids without blocking the pore mouth of ZSM-12. About $24 \%$ of the external acids, as well as $16 \%$ of the internal acids, were lost after silanization (Fig. S5 $\dagger$ ). As a result, the conversion of methanol dropped from 95\% (pristine) to $70 \%$ after a reaction time of $5 \mathrm{~h}$. In addition, the $\mathrm{C}_{9} / \mathrm{C}_{9}{ }^{+}$ ratio increased by 3-6 times after silanization over the entire reaction period (Fig. 3d), whereas the selectivity of the aromatics (in the liquid product) remained high (>95\%). These results indicated that the transformation of $\mathrm{C}_{9}$ species into MMBs depends on the amounts and strengths of the external acids. In addition, when the external surface covered the coke, the $\mathrm{C}_{9} / \mathrm{C}_{9}{ }^{+}$ratio decreased significantly with reaction time, independent of whether the catalyst had been treated by silanization or not. This implied that, even in the final stages of the reaction, there were still sufficient external acids to ensure the high selectivity of MMBs via alkylation.

The coke formation rate of ZSM-12, calculated using the TGA data (Fig. 4a), was very high (17.3 $\left.\mathrm{mg} \mathrm{g}_{\text {cat }}{ }^{-1} \mathrm{~h}^{-1}\right)$ over the induction period (initial $5 \mathrm{~h}$ ), which validates the building of the hydrocarbon pool inside the channel. This value decreased to $8.97 \mathrm{mg} \mathrm{g}_{\text {cat }}{ }^{-1} \mathrm{~h}^{-1}$ from $5-15 \mathrm{~h}$, but was still far higher than that (a)

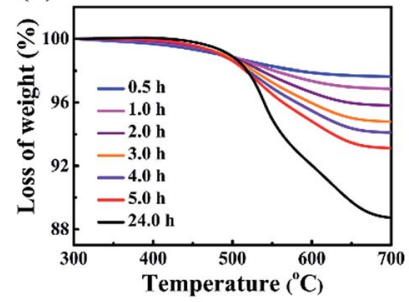

(c)
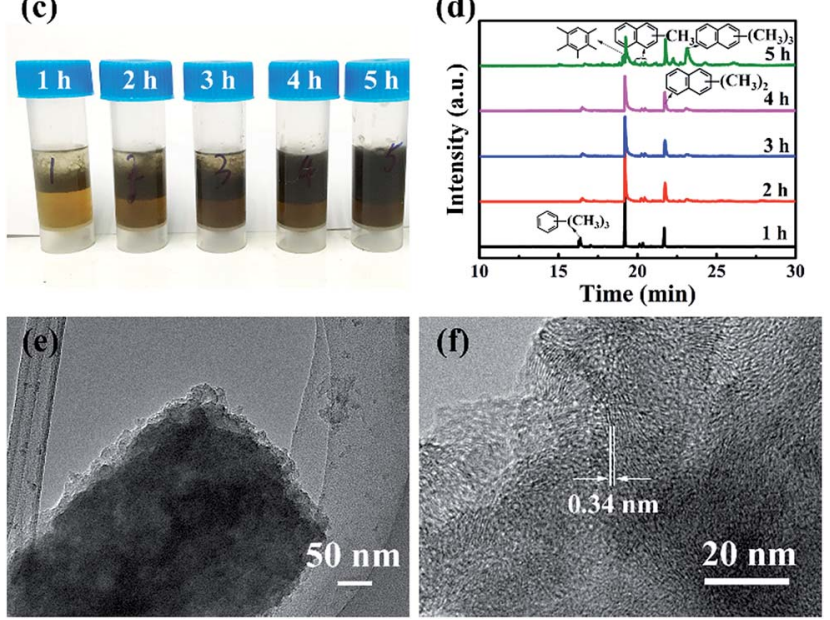

(b)

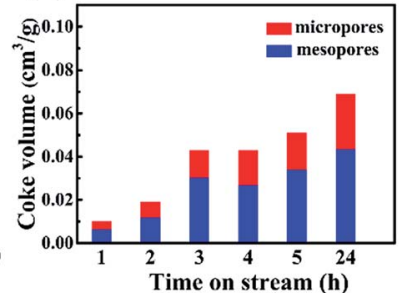

(d)
Fig. 4 (a) Time-dependent TGA analysis of the spent Zn/ZSM-12 catalyst used in the MTA reaction. (b) Pore volume of ZSM-12 after different reaction times. (c) Photographs of the spent catalysts after being dissolved in $15 \% \mathrm{HF}$ and extracted by $\mathrm{CH}_{2} \mathrm{Cl}_{2}$. (d) $\mathrm{GC}-\mathrm{MS}$ chromatograms of the organic species in the spent catalysts extracted by $\mathrm{CH}_{2} \mathrm{Cl}_{2}$. (e) and (f) TEM images of the remaining carbon structure after using $15 \% \mathrm{HF}$ solution to dissolve the spent Zn/ZSM-12 catalyst.

(3.8 $\mathrm{mg} \mathrm{g} \mathrm{g}_{\text {cat }}{ }^{-1} \mathrm{~h}^{-1}$ within $76 \mathrm{~h}$ ) of nanosized ZSM-5. ${ }^{25}$ The higher coke formation rate with ZSM-12 is due to its 1-D channel, which is different from the dual diffusion channels of ZSM-5. Assuming that the density of coke is $1.22 \mathrm{~g} \mathrm{~cm}^{-3}$, the timedependent ratios of coke in the different pores were estimated (Fig. 4b). The weight ratio of coke was $71 \mathrm{mg} \mathrm{g}_{\text {cat }}{ }^{-1}$ after a reaction time of $5 \mathrm{~h}$, and the micropore volume of ZSM-12 decreased to $0.0169 \mathrm{~cm}^{3} \mathrm{~g}^{-1}$. Considering that the micropore of ZSM-12 only holds $20.6 \mathrm{mg}$ coke per gram, the remaining $50.4 \mathrm{mg}$ of coke (per gram) should deposit on the external surface or stacking pores of ZSM-12. For the completely deactivated sample, $43.8 \%$ of the coke deposited in the micropores and the remaining $56.2 \%$ deposited outside (Fig. 4 b). In contrast, most of the coke (about 89\%) deposited in the mesopores of nanosized ZSM-5. ${ }^{25,28,29}$ The quicker coke deposition in the micropores of ZSM-12 explained well the formation of very few MMBs and poly-aromatics, extracted by $\mathrm{CH}_{2} \mathrm{Cl}_{2}$ (Fig. $4 \mathrm{c}$ and d). In addition, the coke-deposited ZSM-12 was treated by HF solution, which dissolved the Si and $\mathrm{Al}$ species completely and only left carbon species. The carbon structure retained the morphology of the pristine ZSM-12 (Fig. 4e and f), which is apparently different from the carbon cage formed with nano ZSM-5. ${ }^{25}$

Considering that the coke fully occupied the micropores of ZSM-12 over time, we were able to determine the free pore size of the 1-D channel of ZSM-12 at different reaction times. Coke 
occupied $50 \%$ of the micropores in the initial $5 \mathrm{~h}$, and the pore size sustainably decreased from $0.59 \mathrm{~nm}$ to $0.551 \mathrm{~nm}$ (at $1 \mathrm{~h}$ ) and to $0.474 \mathrm{~nm}$ (at $5 \mathrm{~h}$ ) (Fig. S6 $\dagger$ ). At $24 \mathrm{~h}$, the free pore size was $0.33 \mathrm{~nm}$ and around $67 \%$ of the micropores were occupied. It is apparent that although progressive pore filling occurred, the free pore size of ZSM-12 at 5-10 h still allows the free diffusion of $\mathrm{B}, \mathrm{T}$ and $\mathrm{PX}$ with sizes of $0.5 \mathrm{~nm}$. In addition, $\mathrm{X}$ and triMB are two species that are much more active than $\mathrm{B}$ and $\mathrm{T}$ thermodynamically, via the hydrocarbon pool mechanism. ${ }^{30}$ However, the selectivity of PX in X using ZSM-12 was 50-60\% after 5-10 h, which was larger than the equilibrium ratio (about 23-24\%) (Fig. S7†). Apparently, when the coke-deposited ZSM-12 exhibits a shape selective effect on PX formation, it is impossible to produce triMB in large amounts inside the pore. In this case, we confirmed that $\mathrm{X}$, and not triMB, was the primary product when using ZSM-12, and its continuous alkylation contributed to the formation of MMBs in high selectivity (Fig. 1a). It also explained well the low $\mathrm{C}_{9} / \mathrm{C}_{9}{ }^{+}$ratio after $2-5 \mathrm{~h}$ (Fig. 3d).

In addition, we examined the aromatic product distribution by treating the ZSM-12 based catalyst under 100\% steam at $660{ }^{\circ} \mathrm{C}$ for $4 \mathrm{~h}$. The steam-treated catalyst exhibited similar crystalline characteristics to those of the pristine sample in the XRD pattern (Fig. S8 $\dagger$ ), indicating the high stability of the skeleton structure of ZSM-12. Although the acidic density of the catalyst was greatly decreased by the steam treatment, which is a normal trend for all kinds of zeolites, ${ }^{31,32}$ the selectivity of MMBs was still $60 \%$ of all the aromatics (Fig. S9 and S10†). The results proved that the structural effect (the huge external surface of the nano zeolite) played the dominant role in the high selectivity of MMBs, compared to the acidic effect. In addition, the steam treatment gave a catalyst with a low acidic strength and low density, which may exhibit a similar effect on the product selectivity to that of the $\mathrm{Si} / \mathrm{Al}$ ratios of the zeolite. Therefore, further investigation is needed. With regards to the difference between ZSM-5 and ZSM-12, the yield of $\mathrm{C}_{6}-\mathrm{C}_{8}$ aromatics for the former is $16-18 \%,{ }^{10}$ which is higher than that $(1.08 \%)$ obtained for the latter which was used in the present work. In this case, the consecutive alkylation on the external surfaces of different zeolites may be different, thus explaining well the low yield of MMBs with nano ZSM-5 (Tables S1 and S2 $\dagger$ ).

In summary, we evaluated the performance of Zn-loading zeolite ZSM-12 with 1-D straight pores in the MTA process. Nanosized ZSM-12 exhibited a long lifetime of up to $20 \mathrm{~h}$ and a high aromatics yield of up to $84.6 \%$ (carbon base), more than $95 \%$ of which are MMBs. We validated that $\mathrm{X}$ is the primary intermediate product inside ZSM-12, and its subsequent alkylation on the huge external surface of the nanosized zeolite achieves the synthesis of MMBs with high selectivity, thus simplifying the synthesis route of MMBs. These results provide new insight into the utilization of the external surface reaction in a controlled way, beyond the shape selectivity effect of zeolites.

\section{Acknowledgements}

The authors are thankful for the support of the NSFC program (21376135, 91434122 and 51236004) and the CNPC Innovation Foundation of 2014D-5006-0506.

\section{Notes and references}

1 Z. Lai, G. Bonilla, I. Diaz, J. G. Nery, K. Sujaoti, M. A. Amat, E. Kokkoli, O. Terasaki, R. W. Thompson, M. Tsapatsis and D. G. Vlachos, Science, 2003, 300, 456-460.

2 J. G. Zhang, W. Z. Qian, C. Y. Kong and F. Wei, ACS Catal., 2015, 5, 2982-2988.

3 X. Zhang, D. Liu, D. Xu, S. Asahina, K. A. Cychosz, K. V. Agrawal, Y. Al Wahedi, A. Bhan, S. Al Hashimi, O. Terasaki, M. Thommes and M. Tsapatsis, Science, 2012, 336, 1684-1687.

4 M. Moliner, C. Martínez and A. Corma, Angew. Chem., Int. Ed., 2015, 54, 3560-3579.

5 Z. Wang, L. Ci, L. Chen, S. Nayak, P. M. Ajayan and N. Koratkar, Nano Lett., 2007, 7, 697-702.

6 Y. Bhawe, M. Moliner-Marin, J. D. Lunn, Y. Liu, A. Malek and M. Davis, ACS Catal., 2012, 2, 2490-2495.

7 S. Ilias and A. Bhan, J. Catal., 2012, 290, 186-192.

8 T. Wang, X. P. Tang, X. F. Huang, W. Z. Qian, Y. Cui, X. Y. Hui, W. Yang and F. Wei, Catal. Today, 2014, 233, 8-13. 9 K. Shen, W. Z. Qian, N. Wang, C. Su and F. Wei, J. Am. Chem. Soc., 2013, 135, 15322-15325.

10 Y. H. Ma, N. Wang, W. Z. Qian, Y. Wang, J. M. Zhang and F. Wei, RSC Adv., 2016, 6, 81198-81202.

11 N. Wang, W. Z. Qian, K. Shen, C. Su and F. Wei, Chem. Commun., 2016, 52, 2011-2014.

12 C. Dai, S. Zhang, A. Zhang, C. Song, C. Shi and X. Guo, J. Mater. Chem. A, 2015, 3, 16461-16468.

13 J. Gu, Z. Zhang, P. Hu, L. Ding, N. Xue, L. Peng, X. Guo, M. Lin and W. Ding, ACS Catal., 2015, 5, 6893-6901.

14 D. Farrusseng and A. Tuel, New J. Chem., 2016, 40, 3933-3949.

15 K. Liang, C. J. Coghlan, S. G. Bell, C. Doonan and P. Falcaro, Chem. Commun., 2016, 52, 473-476.

16 T. Otto, S. I. Zones and E. Iglesia, J. Catal., 2016, 339, 195-208. 17 S. B. Pu and T. Inui, Appl. Catal., A, 1996, 146, 305-316.

18 J. T. Li, L. L. Lou, C. L. Xu and S. X. Liu, Catal. Commun., 2014, 5, 97-100.

19 C. Paris, N. Martín, J. Martínez-Triguero, M. Moliner and A. Corma, New J. Chem., 2016, 4, 4140-4145.

20 U. Olsbye, S. Svelle, M. Bjorgen, P. Beato, T. V. Janssens, F. Joensen, S. Bordiga and K. P. Lillerud, Angew. Chem., Int. Ed., 2012, 51, 5810-5831.

21 Y. Wang, Y. Song, W. Huo, M. Jia, X. Jing, P. Yang, Z. Yang, G. Liu and W. Zhang, Chem. Eng. J., 2012, 181-182, 630-635.

22 M. R. Rahimpour, M. Jafari and D. Iranshahi, Appl. Energy, 2013, 109, 79-93.

23 S. Gopal, K. Yoo and P. G. Smirniotis, Microporous Mesoporous Mater., 2001, 49, 149-156.

24 M. Bernauer, E. Tabor, V. Pashkova, D. Kaucký, Z. Sobalík, B. Wichterlová and J. Dedecek, J. Catal., 2016, 344, 157-172.

25 K. Shen, W. Z. Qian, N. Wang, C. Su and F. Wei, J. Mater. Chem. A, 2014, 2, 19797-19808.

26 S. Zheng, H. R. Heydenrych, A. Jentys and J. A. Lercher, J. Phys. Chem. B, 2002, 106, 9552-9558.

27 J. A. Howarter and J. P. Youngblood, Langmuir, 2006, 22, 11142-11147. 
28 M. Choi, K. Na, J. Kim, Y. Sakamoto, O. Terasaki and R. Ryoo, Nature, 2009, 461, 246-249.

29 K. Shen, W. Z. Qian, N. Wang, J. Zhang and F. Wei, J. Mater. Chem. A, 2013, 1, 3272-3275.

30 S. Svelle, F. Joensen, J. Nerlov, U. Olsbye, K. P. Lillerud, S. Kolboe and M. Bjørgen, J. Am. Chem. Soc., 2006, 128, 14770-14771.
31 J. G. Zhang, W. Z. Qian, X. P. Tang, K. Shen, T. Wang, X. F. Huang and F. Wei, Acta Phys.-Chim. Sin., 2013, 29, 1281-1288.

32 Y. H. Ma, D. L. Cai, Y. R. Li, N. Wang, M. Usman, C. Anna, D. Tang, W. Z. Qian, Y. Wang, D. S. Su and F. Wei, RSC Adv., 2016, 6, 74797-74801. 